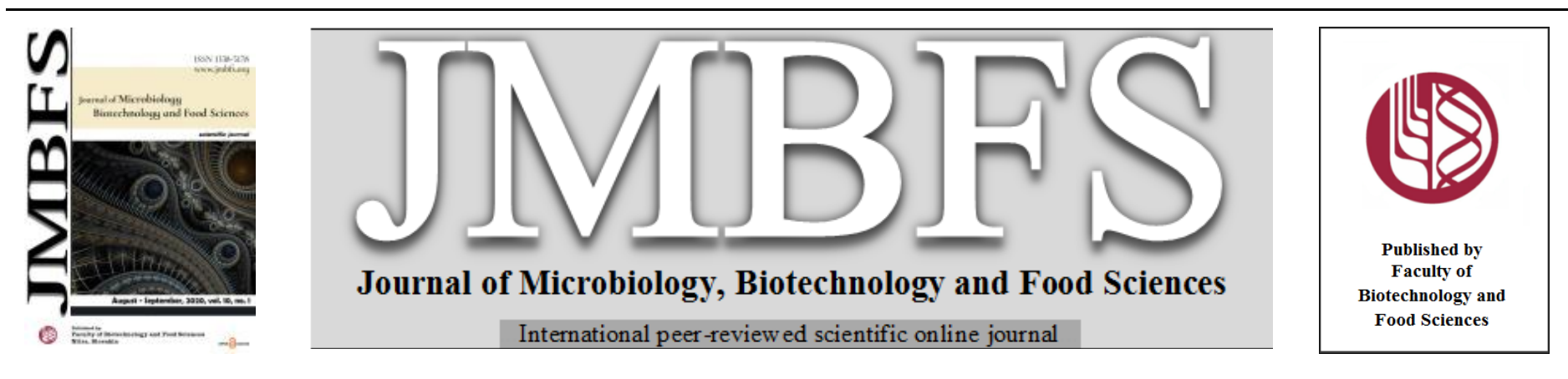

\title{
A REVIEW ON RECENT TRENDS OF ULTRASOUND ASSISTED PROCESSING IN FOOD SEGMENT
}

\author{
Smriti Ambadgatti ${ }^{1}$, Sonal Patil ${ }^{*}$, Ashish Dabade ${ }^{1}$, Arya $S^{2}$, Pravin Bhushette $^{1,2}$, Sachin K Sonawane ${ }^{1}$ \\ Address(es): \\ ${ }^{1}$ School of Biotechnology and Bioinformatics, D. Y. Patil University, Navi Mumbai, India. \\ ${ }^{2}$ Food Engineering and Technology Department, Institute of Chemical Technology, NM Parekh Marg, Matunga, Mumbai, India.
}

*Corresponding author: $\underline{\text { sac007s@gmail.com }, \text { ppsonal@ rediffmail.com }}$

doi: 10.15414/jmbfs.2020.10.1.1-4

ARTICLE INFO

Received 12. 4. 2019

Revised 17. 2. 2020

Accepted 19. 2. 2020

Published 1. 8. 2020

\section{Review}

open $\mathcal{O}$ access

\section{INTRODUCTION}

The normal human audible range is 20 to $20000 \mathrm{~Hz}$ and above $(>20 \mathrm{kHz})$ acoustic (sound) waves define as ultrasound waves. Acoustic cavitation (AC) is the reaction between the liquid medium, ultrasonic waves, and dissolved gas molecules when an ultrasound is passed through the liquid. Due to a fluctuating pressure, under the effect of acoustic field, the nuclei of the dissolved gas molecules oscillate. The dispersion of solvent vapor and soluble gas molecules at outside of oscillating bubbles takes place during these oscillations. The diffusion of gas/vapor into bubbles at expansion phase is higher than that of compression phase of the bubble oscillations which is known as the "rectified diffusion" process. The bubbles grow in size and approach a resonance size range. In a period of one acoustic cycle, the bubbles which have attained the resonance size, build up to a maximum size and collapse vigorously and induce a tremendously high temperature. Theoretically, the predicted evaluation gives a value of $100,000 \mathrm{~K}$, but the experimentally determined temperature ranges from $2000-$ $10,000 \mathrm{~K}$. apart from the chemical reactions, physical forces such as turbulence, shock waves, shear forces, and micro-jets also originate from acoustic cavitation (Chandrapala et al., 2012).

Ultrasound being non-toxic and ecofriendly is an emerging technology which is considered as green technology as it consumes less energy (Majid et al., 2015) The medium through which the ultrasound travels is also very important as it helps to determine the properties of the ultrasound. The intense physical forces that are used for a number of applications such as tenderization of meat products, filtration, and food emulsions of food ingredients are generated from acoustic streaming, cavitation, shear, micro-jet and shock waves in liquid media (Zou et al., 2018). The physical and chemical repercussions of acoustic cavitation also affect the functional properties of starch, protein and other food components (Zou et al., 2018). Even though the applications of ultrasound in food processing have a wide range, it is used in a constrained manner.

\section{ULTRASONICATION EFFECT ON HYDRATION PROPERTIES}

In the food industry many operations such as cooking, tempering, wet milling, malting, extraction, and fermentation based on hydration. Hydration of agricultural products is very necessary for enrichment but as it is in complex system consume time. So, overcome this issue can be solved by using various technologies and methodologies like microwave, irradiation technology, ultrasound, hydrostatic pressure, cyclical pressure, and high temperature which enhance hydration process. But ultrasound is reported as efficient tool to boost hydration process (Miano \& Augusto, 2018). They also studied the effect of ultrasound treatment i.e US1 $(25 \mathrm{kHz}, 360 \mathrm{~W})$, and US2 $(40 \mathrm{kHz}, 480 \mathrm{~W})$ within range of temperature $\left(30\right.$ to $\left.70^{\circ} \mathrm{C}\right)$ on hydration of wheat where reduction in enthalpy change, activation energy, and the Gibbs free energy with increased in entropy. Activation energy is defined as the minimum energy threshold that the reacting species should acquire so that the chemical reaction can take place. The decrease in activation energy which enhances hydration rate as ultrasound treatment increases due to decreasing of diffusion resistance in hydration process (Shafaei et al., 2018). These helps to understand the mass and heat transfer associetd with ultrasonication hydration process of wheat kernel(Shafaei $\boldsymbol{e t}$ al., 2018).

Enthalpy represents the total energy content of a system. It is a state function and is calculated as the sum of the internal energy of a system and the product of the pressure and volume. In a chemical reaction, at constant pressure, heat transfer is equal to the enthalpy change. The decrease in enthalpy where energy absorbs by wheat kernel results in enhancement of hydration rate in which contribution of ultrasound treatment results in the formation of the activated complex (Miano et al., 2018; Shafaei et al. 2018).

Gibbs free energy is a thermodynamic state function and is defined as a measure of the potential of reversible or maximal work that is done by a system at constant temperature and pressure. It is calculated as the enthalpy minus the product of entropy and absolute temperature. As Gibbs free energy changes which result in the enhancement of hydration rate which is base on the decrease in the enthalpy (Shafaei et al. 2018).

Entropy is often described as the degree of disorder or randomness. Entropy primarily illustrates the energy dissipation in a process. Increase in entropy which indicates an increase in hydration rate as ultrasound treatment causes chaotic and turbulence movement of molecules, the organization of the molecules during the activated complex formation (Miano et al., 2018; Shafaei et al. 2018).

\section{EFFECT OF ULTRASOUND ASSISTED COOKING ON CHEMICAL PROPERTIES OF FOOD}

The consumer preference for buying meat products are inclined towards the meat characteristics and tenderness of the meat along with the taste and flavor. Spiced beef products are very rich in taste and flavor and are very popular in China. The cooking method of spiced beef affects the formation of flavor compounds in the product, which in turn affects the chemical and nutritional properties (Zou et al. 2018). Zou et al. (2018) investigated the effect of ultasonication power on ultrasound-assisted cooking on chemical properties of spiced beef treating with different power of ultrasound $0-1000 \mathrm{~W}$ (with frequency of $20 \mathrm{kHz}$ ) for 120 min which shows significant increased in free amino acids (FAAs), increased in sodium chloride, sugar, volatile flavor substance like aldehydes and ketoes.

The sodium chloride content in the beef sample is increased in the ultrasound treatment with increase in the power due to increase the permeability of muscle 
tissue (Lealramos et $\boldsymbol{a l}$., 2011), diffusivity of $\mathrm{NaCl}$ and moisture enhancement (Ozuna et al., 2013). Its jointly effect such as cavitation and mechanical effect which could boost the penetration efficiency of brine soup foremost to improved saline taste (Zou et al., 2018).

The cavitation, thermal, and mechanical, effects of ultrasound are responsible for increasing the sugar content in the beef treated with ultrasounds (Zou et al. 2018), due to the destruction of myofibril structure which is responsible for increasing the space between the myofibrils (Kang et al., 2016).

The essential amino acid content and the ratio of essential amino acid/non essential (E/NE) was increase during the ultrasonication treatment (Zou et al. 2018). The effect of ultrasound treatment diminishes total amino acid content, especially Asp and Glu (Zou et al., 2018). During the brining process of beef, ultrasound causes cavitation in liquid foods which encourage the water molecules to crack to free radicals which enhance protein degradation (Kang et al., 2016; Kang et al., 2017).

When lipid oxidation took place, there was a rise in the TBARS value, but no particular deviation was observed with the use of different ultrasonic power groups. The relative content of volatile flavor components, particularly aldehydes, alcohols, and ketones showed a significant increase $(\mathrm{P}<0.05)$ when exposed to ultrasonic treatment but there was no change with the use of different power groups $(\mathrm{P}>0.05)$. It was concluded that ultrasonic treatment had a positive effect on the chemical profiles of spiced beef when a power of $800 \mathrm{~W}$ was applied (Zou et al., 2018)

The Chinese rice is used in the production of wine in food industry, during the processing water absorption velocity is most important factor considered which describe the characteristics of cooking and processing. Soaking of rice is first step before production of wine in which circulation of water uniformly that leads to improvement of textural characteristics of cooked rice. This process also assistances to expand the utilization of microorganism during brewing, but disadvantage of these process is that it is time-consuming, so the technology is required to improve the hydration properties which enhance the wine production from rice. Li et al. (2019) were observed the significant improvement in the physicochemical properties and hydration in Chinese brewing rice treated with high ultrasonic power. The ultrasonication rice helps to reduce the hardness of rice, time for cooking, enhance water binding capacity, and gelatinization degree (Li et al., 2019). The ultrasonication treatment during the soaking increases the contact area between the water and rice which accelerates the penetration of water into the rice due to rise in the micropores on the surface of rice ( $\mathbf{L i}$ et al., 2019) which further confirm by scanning electron microscope which showed that soaking led to lose the internal structure of rice. Miano et al. (2016) also reported that ultrasonic treatment enhances the porosity in grains due to the formation of micro-channels inside the grains. Hence, ultrasonication assisted soaking facilitates characterizes of brewing rice with reducing time of fermentation, soaking and boiling.

\section{ROLE OF ULTRASOUND AS PRESERVATION IN FOOD TO} INACTIVATE PATHOGENS

Recently, the application of high-intensity ultrasound as a sterilization technique widely used to decontaminate microorganism which ensures the safety of food product and also alternative for utilization of chemical additives in food preservation (Sarkinas et al., 2018). Sarkinas et al., (2018) investigate the effect of high power $600 \mathrm{~W}$ and $300 \mathrm{~W}$ for 10 to $30 \mathrm{~min}$ at $28 \mathrm{kHz}$ on phytoviruses and vegetative cells of both gram-positive and gram-negative bacterial cells which results to 1.59 to $3.4 \log$ reduction in bacterial suspensions.

The healthy as well as damaged tissues of highly perishable products act as an outstanding substrate and favor the growth of spoilage as well as pathogenic phytoviruses. These phytoviruses cause several diseases to human society. Over a period of several years, synthetic chemicals are being used to increase the microbiological safety of harvested commodities. It is a known fact that these chemicals are misused on agricultural products which might jeopardize the health of the people consuming the goods. The food industry is now looking forward to other non-chemical methods such as ultraviolet light, heat treatment, and some biological control methods and ultrasound as alternatives to chemicals because some of the pathogens are growing resistant to the chemicals (Ma et al., 2017, Usall et al., 2016).

During the study, it was found that gram-positive bacteria such as B. cereus and L. monocytogenes are more vulnerable to ultrasonic treatment than gramnegative bacteria such as E. coli and $S$. Typhimurium. it was also found that using $600 \mathrm{~W}$ ultrasonic power was more effective than $300 \mathrm{~W}$. Unfortunately, ultrasonic treatment cannot be used alone as it does not produce the necessary lethal effect. The ultrasonic treatment has to be combined with other methods such as thermal to get the desired result. The set up utilized for the inactivation of bacterial cells are shown in fig 1(Sarkinas et al., 2018).

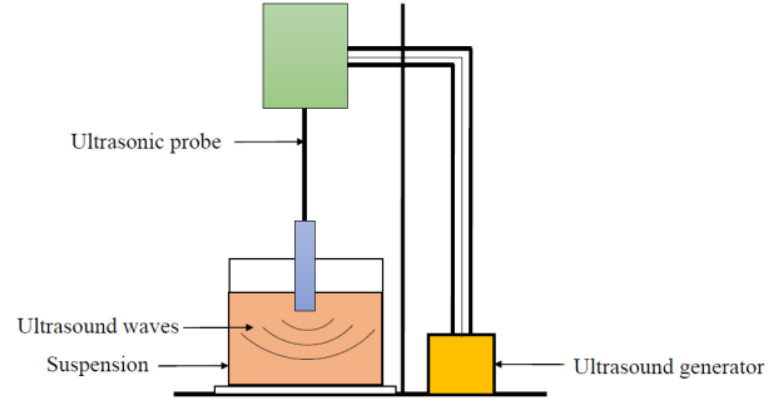

Figure 1 Ultrasonication setup

\section{POSTHARVEST DISINFECTION}

In the past few years, consumers, health organizations, as well as government agencies, are stressing more and more on consuming fresh fruits and vegetables (FFVs) for a healthy diet. This creates the need for the increase in the quality and safety of FFVs. Washing with water and other chemical solutions is primarily being used for disinfection in harvesting, post-harvest handling, processing and transportation; i.e., the production line. Chlorinated solutions have many benefits such as stability, low cost, water solubility, and simple handling over a long period of storage time. But chlorine is known to form potentially mutagenic and carcinogenic by-products and this puts a limitation on its use. Use of chlorine solution on fresh goods is banned in some of the European countries because it has been found that some of the microorganisms can tolerate chlorine treatment (Montalvo-González et al. 2018). Finding a water-based disinfection method to use on FFVs is still a persisting problem because some of the bacteria tend to adhere or are entrapped to the surface of the FFVs and difficult to treat with most of the sanitizers (Montalvo-González et al. 2018).

The use of ultrasound to clean surfaces has been proved to be successful in the electronics industry. So, it was thought to give a try to use ultrasound as an alternative for chlorinated solutions for FFVs. Seymour et al. (2002) were the first one to investigate the effect of ultrasound on post-harvest disinfection, and since then, several attempts have been made to study the effect of ultrasound combined with chemical solutions on FFVs. Chlorinated solutions could be completely replaced with ultrasound because of the side effects of using chlorinated solutions. Organic sanitizers such as lactic acid, citric acid, malic acid, peracetic acid, and some others have been known to reduce the microbial populations to a significant value when used in combination with ultrasound (Montalvo-González et al., 2018)

\section{ULTRASOUND-ASSISTED PRETREATMENT}

\section{Pretreatment to reduce food waste}

Recently the application of ultrasound treatment is noted in the reduction of food waste in which valuable product like glucose is recovered from the ultrasonicated treated food waste ( $\mathbf{L i}$ et al., 2018). Improvement in the yield of glucose is due to reduction of size in waste, and also the hydrolysis time is decreased by the ultrasound pretreatment (Li et al., 2018).

Pretreatment to reduce the formation of acrylamide in fried product

Acrylamide is listed as a carcinogenic compound by International Agency of Research on Cancer (IARC, 1994) which form during the frying where temperature is above $120^{\circ} \mathrm{C}$. Basically, this is a non-enzymatic reaction between asparagine amino acid and reducing sugars (Friedman, 2003). Antunes-Rohling et al. (2018) used ultrasound water bath for pre-treatment for soaking of potato which results in $90 \%$ acrylamide reduction which is due to the decrease in reducing sugars.

\section{Utilization of ultrasound as peeler treatment}

The shell of the shrimp (Pandalus borealis) looses with the power of ultrasound i.e. frequency of 24 with addition of proteolytic enzyme and these pretreatmen emerge as peeler. During this process cavitation bubbles pitted the shrimp shell which is responsible for creating pathways to diffuse enzyme into muscle-shell (Dang et al. (2018).

\section{ULTRASOUND ASSISTED EXTRACTION}

Ultrasonic extraction is one of the widely used extraction technique due to its low processing cost, ease handling and good efficient (Jing, 2008). Huang et al (2009) studied extraction flavonoids from the $F$. eucommiae and reported that Ultrasonic extractions give higher extraction than the conventional, microwaveassisted, enzyme assisted extractions. Zhang et al. (2009) studied epimedin C extraction from the leaves of Epimedium by ultrasonic extraction and soxhlet extraction method. They found that the Ultrasonic extraction gives higher yield that of soxhlet extraction. They also stated that ultrasound extraction requires less 
extraction time, temperature and solvent. Similar result,reduction in extraction time increased yield were also reported by Cao et., al. (2009) for extraction of piperine from white pepper and by Jing et.al. (2015) for extraction of flavonoid and antioxidants from Alfalfa. Ultrasound extraction found to be a more effective extraction technique for extraction of different compounds.

\section{ULTRASOUND ASSISTED PROCESSING}

Ultrasound technology has come to the food processing industry as a boon as it does not tamper with the organoleptic properties of food. It is time-efficient, inexpensive, cuts down the wastewater post-treatment and helps produce purer final products. Use of ultrasound in the processing industry has resulted in micromixing, and more efficient mixing, rapid mass, and heat transfer helped in cutting down the temperature, selective extraction, downsized the equipment size and also increased the rate of production. Foams and agglomerates can be formed; the dust can be precipitated out; filtration efficiency could be improved using ultrasound.

\section{Drying}

Drying is the process by which the water activity of food products is decreased to a level such that the growth of microorganisms and enzymatic reactions are hindered. Drying is a useful operation as it extends the shelf life of the food, but it also has certain disadvantages (Rodríguez et al., 2018). Drying cannot be efficiently used on heat sensitive products because using high temperatures will damage the food and using low temperatures extend the time which corresponds to the initiation of oxidation reactions and the quality of the food is reduced. Due to this reason, alternative technologies are being studied in the food industry (Rodríguez et al., 2018).

The utilization of ultrasonication in food processing is being considered as a novel and auspicious technology. The efficiency of drying assisted by power ultrasound can be accomplished by adjusting the product behavior at the time of drying, pretreatments such as soaking the food product in an acoustically assisted liquid medium or by exposing it to power ultrasound in gaseous medium (Reference). The use of power ultrasound during drying has both positive and negative effects. The positive effects being the intensification of the drying process and limitation of oxidation reactions which in turn retain most of the bio compounds when applied at low temperatures. At high temperatures, the synergy of thermal and acoustic energy affects the bio compounds negatively.

The power ultrasound operation has proved to be highly effective in the preservation of food and is highly advantageous non-thermal processing technique. But power ultrasound also has its own drawbacks. The propagation of ultrasonic waves in air medium is one of the challenges and also limits the energy used for drying. Another major hindrance in using power ultrasound for drying is managing the interaction between the foodstuff and the ultrasonic waves because ultrasound can encourage structural and nutritional damage to the food (GarcíaPérez et al., 2007)

\section{Freezing}

Freezing is generally used as a method of preservation of food to store for months or over a year, which depends on type of food. When spoilage of food occurs, objectionable color and texture changes take place along with some undesirable off-flavors. Freezing delays, the biochemical and physiochemical reactions that are often responsible for these off-flavors by an appreciable amount of time and also helps retain the sensory properties and nutritive properties of fresh foods (Erkmen and Bozoglu, 2016). Freezing methods are classified as follows

Quick freezing: The ice crystals produced during quick freezing are fine and are formed equally within and outside the cell, causing less to no damage to the tissues.

- Slow freezing: this is achieved within 3-72 hours. During this time, larger ice crystals are formed which disrupt the cell structure of the food particles.

In the recent years, research has been done on the applications of ultrasound in the field of low-temperature processes such as freezing, freeze-drying, freeze concentration and thawing to boost the quality of frozen foods (Cheng $\boldsymbol{e t}$ al. 2015). The use of ultrasound has also been studied for controlling the size and size distribution of the ice crystals formed during the freezing process and to study the ice content and pace of freezing by using low-intensity ultrasound. Generally, two types of ultrasound frequencies are used (Cheng et al., 2015)

- Low-intensity diagnostic ultrasound: these ultrasound waves have a frequency between 5-10 MHz. This type of ultrasound is normally used as an analytical tool for non-destructive inspection, process control, and quality evaluation. Low-intensity ultrasound is used to determine food properties; for instance, firmness, ice content, total soluble solid, oil content. It is also used for the inspection of the material used for packaging food.

- High-intensity power ultrasound: the frequency of this type of ultrasound ranges between $20-100 \mathrm{kHz}$. This technology is somewhat new in the food industry, and studies are going on about how this technology can be used to benefit the industry.

\section{Germination}

During the germination process there are chances of increasing microbial load which can be prevented by using preservative. So, in such case ultrasound is observe effective to reduce aerobic count by 5.86 and $5.51 \mathrm{log}$ units and also increased the average germination from 83 - 97\% (Chiu and Sung, 2014).

\section{AIRBORNE UST AS ADVANCES IN ULTRASONICATION}

Airborne acoustic ultrasound is a relatively new technology and has been proved efficient in several foods and non-food applications such as drying, defoaming and decontamination. One of the main challenges of using airborne UST is the hindered efficient energy transmission. This problem has been solved by developing several new types of transducers. Airborne UST has been used in the food industry in combination with some old techniques so as to reduce the issues that are faced while using conventional methods. One of the most common examples is of drying. Using high temperature while drying foods has been known to deteriorate the sensory attributes of the products. Hence, using ultrasound-assisted drying is a novel and much better technique. Its makes use of relatively low temperatures and thus preserves the quality and the nutritional value of the food products. Another area where application of airborne UST is famous is inactivation of microorganisms. This method is found to be less damaging to the food products as compared to the conventional methods of pasteurization and sterilization. The use of airborne UST has been studied greatly in the past few years and is successful in several different food industry applications (Clementine et al., 2017)

\section{CONCLUSION}

The ultrasonication technology effectively acts as preservation technology by inactivating microorganisms. This technology effectively can be used in the reduction of acrylamide content in the fried product, postharvest disinfection, pretreatment as peeler. This technology is also suitable for bioconversion from food waste like producing glucose and also helps to reduce or move towards zero waste. There is still scope to understand the effect of ultrasonication effect in modification of proteins and peptides or its extraction and hydrolysis process which need to be investigated. There is huge scope to study the effect of ultrasonication in the area of fermented products like semi-viscous liquid-like idli batter, and various fermented alcoholic beverages fermented the tea, etc Modeling, Software developments, design and fabrication are tools which need to be considered with gerneralized equation to employed ultrasonication as effect scale process in the area of food industry.

Conflict of Interests: Authors do not have any conflict of interest

\section{REFERENCES}

Antunes-Rohling, A., Ciudad-Hidalgo, S., Mir-Bel, J., Raso, J., Cebrián, G., \& Álvarez, I. (2018). Ultrasound as a pretreatment to reduce acrylamide formation in fried potatoes. Innovative Food Science \& Emerging Technologies, 49, 158169. https://doi.org/10.1016/j.ifset.2018.08.010

Cao, X., Ye, X., Lu, Y., Yu, Y., \& Mo, W. (2009). Ionic liquid-based ultrasonicassisted extraction of piperine from white pepper. Analytica Chimica Acta, 640(1-2), 47-51

Chandrapala, J., Oliver, C., Kentish S., \& Ashokkumar M. (2012). Ultrasonics in food processing. Trends in Food Science \& Technology, 19 (5), 975-983. https://doi.org/10.1016/j.ultsonch.2012.01.010

Cheng, X., Zhang, M., Xu, B., Adhikari, B., Sun. J. (2015). The principles of ultrasound and its application in freezing related processes of food materials: A $\begin{array}{llll}\text { review. Ultrasonics } & \text { Sonochemistry, } & 27, & 576-\end{array}$ https://doi.org/10.1016/j.ultsonch.2015.04.015

Chiu, K. Y.,\& Sung, J. M. (2014). Use of ultrasonication to enhance pea seed germination and microbial quality of pea sprouts. International Journal of Food Science and Technology, 49, 1699-1706. https://doi.org/10.1111/ijfs.12476

Clementine M.G.C, Ojha, K. S., O'donnell, C. P., Cardoni, A., \& Tiwari, B. K (2017). Applications of airborne ultrasonic technology in the food industry. $\begin{array}{llll}\text { Journal of } & \text { Food } & \text { Engineering, 208, }\end{array}$ https://doi.org/10.1016/j.jfoodeng.2017.03.030

Danga, T.T., Gringer, N., Jessen, F., Olsen, K., Bøknæs, N., Nielsen, P.L., \& Orlien, V. (2018). Facilitating shrimp (Pandalus borealis) peeling by power ultrasound and proteolytic enzyme. Innovative Food Science \& Emerging Technologies, 47, 525-534. https://doi.org/10.1016/j.ifset.2018.04.019

Erkmen, O., \& Bozoglu, T.F. (2016). Chapter 3 Food Preservation by Low Temperatures, Food Microbiology: Principles into Practice, Online ISBN: 9781119237860, https://doi.org/10.1002/9781119237860.ch29

Friedman, M.. (2003).. Chemistry, biochemistry and safety of acrylamide. A review. Journal of Agricultural and Food Chemistry, 51, 4504-4526. https://doi.org/10.1021/jf030204 
García-Pérez, J. V., Cárcel, J. A., Benedito, J., Mulet, A.. (2007).. Power ultrasound mass transfer enhancement on food drying. Food and Bioproducts Processing, 85, 247-254. https://doi.org/10.1205/fbp07010

IARC. International Agency for Research on Cancer. (1994). Monographs on the valuation of carcinogen risk to humans: Some industrial chemicals. Nr 60. Lyon: IARC

Jing, W., Baoguo, S., Yanping, C., Yuan, T., \& Xuehong, L. (2008) Optimisation of ultrasound-assisted extraction of phenolic compounds from wheat bran. Food Chemistry, 106, 804-810 https://doi.org/10.1016/i.foodchem.2007.06.062

Jing, C.L., Dong, X.F., Tong, J.M. (2015). Optimization of Ultrasonic-Assisted Extraction of Flavonoid Compounds and Antioxidants from Alfalfa Using Response Surface Method. Molecules,20(9), 15550-15571. https://doi.org/10.3390/molecules200915550

Kang, D.C., Wang, A.R., Zhou, G.H., Zhang, W.G., Xu, S.M., \& Guo, G.P. (2016). Power ultrasonic on mass transport of beef: Effects of ultrasound intensity and $\mathrm{NaCl}$ concentration. Innovative Food Science \& Emerging Technology, 35, 36-44. https://doi.org/10.1016/j.ifset.2016.03.009

Kang, D.C., Gao, X.Q., Ge, Q.F., Zhou, G.H., \& Zhang, W.G. (2017). Effects of ultrasound on the beef structure and water distribution during curing through protein degradation and modification. Ultrasonication Sonochemistry, 38, 317 326. https://doi.org/10.1016/i.ultsonch.2017.03.026

Lealramos, M.Y., Alarconrojo, A.D., Mason, T.J., Paniwnyk, L., \& Alarjah, M. (2011). Ultrasound-enhanced mass transfer in Halal compared with non-Hala chicken. Journal of Science and Food Agricultural, 91, 130-133. https://doi.org/10.1002/jsfa.4162

Li X., Mettub S., Martin, J.O., Ashokkumar M., \& Lin, C S. (2018). Ultrasonic pretreatment of food waste to accelerate enzymatic hydrolysis for glucose production. Ultrasonics Sonochemistry (In Press) https://doi.org/10.1016/j.ultsonch.2018.12.035

Li S., Luo Z., Guan, X., Huang K., Li Q., Zhu F., \& Liu J. (2019). Effect of ultrasonic treatment on the hydration and physicochemical properties of brewing rice. Journal of Cereal Science, 87, 78-84. https://doi.org/10.1016/j.jcs.2019.03.002

Ma L., Zhang M., Bhandari B., \& Gao Z. (2017). Recent developments in novel shelf life extension technologies of fresh-cut fruits and vegetables. Trends in $\begin{array}{lllll}\text { Food } \quad \text { Science } & \text { \& } & \text { 64, } 38\end{array}$ https://doi.org/10.1016/j.tifs.2017.03.005

Majid, I., Nayik, G. A., \& Nanda, V. (2015). Ultrasonication and food technology: A review. Cogent Food \& Agriculture, 1071022. https://doi.org/10.1080/23311932.2015.1071022

Miano, A. C., \& Augusto, P. E. D. (2018). The hydration of grains: A critical review from description of phenomena to process improvements. Comprehensive Reviews in Food Science and Food Safety, 17(2), 352-370 https://doi.org/10.1111/1541-4337.12328

Miano, A. C., Sabadoti, V. D., \& Augusto, P. E. D. (2018). Enhancing the hydration process of common beans by ultrasound and high temperatures: Impact on cooking and thermodynamic properties. Journal of Food Engineering, 225(1), 53-61. https://doi.org/10.1016/j.jfoodeng.2018.01.015

Miano, A.C., Ibarz, A., \& Augusto, P.E.D. (2016). Mechanisms for improving mass transfer in food with ultrasound technology: describing the phenomena in two model cases. Ultrasonication Sonochemistry, 29, 413-419 https://doi.org/10.1016/j.ultsonch.2015.10.020

Montalvo-González, E., Luis M. Anaya-Esparza, J., Domínguez-Avila,A., \& González-Aguilar, G. A. (2018). Ultrasonic Processing Technology for Postharvest Disinfection. Postharvest Disinfection of Fruits and Vegetables, 101 119 https://doi.org/10.1016/B978-0-12-812698-1.00005-4

Ozuna, C., A. Puig, J.V. García-Pérez, A. Mulet, J.A., \& Cárcel, (2013) Influence of high intensity ultrasound application on mass transport microstructure and textural properties of pork meat ( Longissimus dorsi ) brined at different $\mathrm{NaCl}$ concentrations. Journal of Food Engineering, 119 84-93. https://doi.org/10.1016/j.jfoodeng.2013.05.016

Rodríguez, O., Eim, V., Rosselló, C., Femenia, A., Cárcel, J. A, \& Simal, S. (2018). Application of power ultrasound on the convective drying of fruits and vegetables: effects on quality. Journal of Science of Food and Agriculture, 98 (5), 1660-1673. https://doi.org/10.1002/jsfa.8673

Sarkinas A, Sakalauskiene K, Raisutis R, Zeime J, Salaseviciene A, Puidaite E, Mockus E, \& Cernauskas D. (2018). Inactivation of some pathogenic bacteria and phytoviruses by ultrasonic treatment. Microbial Pathogenesis, 123, 144-148. https://doi.org/10.1016/j.micpath.2018.07.004

Seymour, I.J., Burfoot, D., Smith, R.L., Cox, L.A., \& Lockwood, A.. (2002) Ultrasound decontamination of minimally processed fruits and vegetables International Journal of Food Science and Technology, 37 (5), 547-557. https://doi.org/10.1046/j.1365-2621.2002.00613.x

Shafaei, S. M., Nourmohamadi-Moghadami A., \& Kamgar, S. (2018). An insight into thermodynamic aspects of ultrasonication effect on hydration mechanism of wheat. Journal of Food Process Engineering, 41 (7), e12862. https://doi.org/10.1111/jfpe.12862
Usall J., Torres R., \& Teixidó N. (2016). Biological control of postharvest diseases on fruit: a suitable alternative?. Current Opinion in Food Science, 11, 51-55 https://doi.org/10.1016/j.cofs.2016.09.002

Huang, W., Xue, A., Niu, H., Jia, Z., \& Wang, J. (2009). Optimised ultrasonicassisted extraction of flavonoids from Folium eucommiae and evaluation of antioxidant activity in multi-test systems in vitro. Food Chemistry, 114, 1147 1154. https://doi.org/10.1016/j.foodchem.2008.10.079

Zhang, H.F., Yang, Xh, Zhao, L.D., \& Wang, Y. (2009). Ultrasonic-assisted extraction of epimedin $\mathrm{C}$ from fresh leaves of Epimedium and extraction mechanism. Innovative Food Science \& Emerging Technologies, 10(1), 54-60. https://doi.org/10.1016/j.ifset.2008.09.007

Zou, Y., Kang, D., Liu,R., Qi, J., Zhou,G., \& Zhang, W. (2018). Effects of ultrasonic assisted cooking on the chemi 